\title{
Effects of Epoxy Adhesive Layer Thickness on Bond Strength of Joints in Concrete Structures
}

\author{
Jaeheum Yeon ${ }^{1, *}$, Yooseob Song ${ }^{2}$, Kwan Kyu Kim ${ }^{3}$ and Julian Kang ${ }^{4}$ \\ 1 Department of Engineering \& Technology, Texas A\&M University-Commerce, Commerce, TX 75429, USA \\ 2 Department of Civil Engineering, The University of Texas Rio Grande Valley, Edinburg, TX 78539, USA \\ 3 North Gyeonggi Branch, Joongbu Division, Korea Conformity Laboratories, Pocheon, Gyeonggi 11184, Korea \\ 4 Department of Construction Science, Texas A\&M University, College Station, TX 77843, USA \\ * Correspondence: jaeheum.yeon@tamuc.edu; Tel.: +1-903-468-8115
}

Received: 3 July 2019; Accepted: 25 July 2019; Published: 27 July 2019

check for updates

\begin{abstract}
In the construction field, adhesives are frequently used to improve adhesion between two objects. Epoxy adhesives are applied as long-term solutions, improving the bond between repair materials and existing concrete structures. Experimental investigations of the relationship between the thickness of an adhesive layer and its shear strength have been conducted by a number of industries outside of the construction sector. However, that research used metal plates as adherends when determining the shear strengths of epoxy adhesives. Therefore, this study examines epoxy adhesives' shear strength development when applied to concrete adherends. The test results show that the thickness of the bond layer did affect shear strength development in the epoxy adhesives examined.
\end{abstract}

Keywords: epoxy adhesive; adhesive layer thickness; slant-shear test; brittle fracture

\section{Introduction}

Concrete and asphalt are representative construction materials used widely in roadway construction. However, since concrete pavement is more durable than asphalt, concrete is most widely employed during the planning stage of roadway construction projects [1]. Unlike asphalt roadways, gaps called transverse joints must be placed at regular intervals on concrete roads, mainly between the concrete slabs. If there are no transverse joints in the concrete, the slabs collide with one another because the volume of the concrete expands when the temperature of the roadway rises [2]. Therefore, the concrete slabs are spaced apart from one another with specific-sized gaps, in order to prevent spall damage (small chunks broken off from the concrete's surface). Such spall damage is not directly related to structural problems with concrete roadway systems. However, if not repaired soon after the damage occurs, it can expand and deepen. Eventually, minor damage can evolve into a major issue. Therefore, spall damage should be repaired in a timely manner.

To fundamentally prevent spall damage at the concrete joints, Coppola et al. [3] developed calcium sulphoaluminate cement-based concrete (which is shrinkage-compensating concrete without Portland cement) for use as jointless concrete slabs. However, this concrete still has limitations if applied worldwide (as is Portland cement). It is particularly sensitive to curing conditions. Thus, an efficient spall damage repair method is still necessary.

The most frequently used repair process for spall damage is called the partial-depth repair method. First, the damaged and undamaged areas are divided using a concrete sawing machine, and the damaged area is demolished using a chipping device. Next, the concrete debris are removed using an air compressor. Before fresh concrete is poured, an epoxy adhesive is applied on top of the existing concrete substrate to improve adhesion [4]. The newly attached concrete patch must be strong enough 
to withstand the forces generated by vehicles running across it. The epoxy adhesive is primarily what holds the concrete patch to the existing concrete substrate, thus providing structural stability.

Epoxy adhesives are frequently used in aerospace, automotive, and offshore industries, and thus are actively being studied in these fields [4]. One topic frequently addressed is the thickness of the adhesive layer. Previous studies [5-16] have experimentally verified that the thickness of the adhesive layer affects its shear strength. ASTM 1002-10 [17] and ASTM D3163-01 [18] were selected as the standard test methods in most of these previous studies, which commonly applied epoxy adhesives to aluminum plates and controlled the adhesive layer thickness in order to measure the shear strength that developed.

In the construction field, Ferdous et al. [19] developed a sandwich panel in which glass fiber reinforced polymer sheets are glued to each side of phenolic foam to serve as a composite railway sleeper. Two railway sleepers are then bonded together with an epoxy-based polymer adhesive consisting of a bisphenol A diglycidyl ether-type epoxy, amine-based curing agent, fire retardant filler, hollow microsphere, and fly ash. To determine the optimum behavior of this adhesive with the railway sleepers developed by Ferodous et al., Taguchi used four parameters: the adhesive's properties, bond length, bond thickness, and bond width. However, the material of the adherend in that study was not concrete. Therefore, we still do not yet know whether the strength that develops is influenced by the epoxy adhesive layer's thickness in the joints of concrete structures.

\section{Research Objective}

The importance of the thickness of the layer of epoxy adhesive is not currently emphasized in concrete structure research. Information is very limited with regards to the effect of adhesive layer thickness on shear strength development when an epoxy adhesive is applied between two concrete surfaces. In the present work, the influence of an adhesive layer's thickness on its shear strength was examined experimentally by applying epoxy adhesives to concrete joints.

\section{Experiment}

\subsection{Test Method}

The British Standard European Norm 12615 (BS EN 12615: Slant-Shear Test using a Cubical Concrete Specimen) [20] was selected to determine the shear strength of the epoxy adhesive applied to a concrete specimen. BS EN 12615 is similar to ASTM C882/C882M [21], also known as the Slant-Shear Test using a Cylindrical Concrete Specimen. ASTM C882/C882M suggests that a cylindrical concrete specimen be used, while BS EN 12615 advises that a prism-shaped concrete specimen be employed. The cylindrical concrete specimen suggested by ASTM C882/C882M can be difficult to control, especially in terms of the slant gap where the epoxy adhesive layer would form, because the specimen must be laid on a flat surface on its side in order to adjust the thickness of the adhesive layer. Cylindrical concrete specimens have a tendency to roll when laid down. Thus, BS EN 12615 was selected as the test method. The specifications of the prism-shaped specimen proposed by BS EN 12615 are shown in Figure 1. 


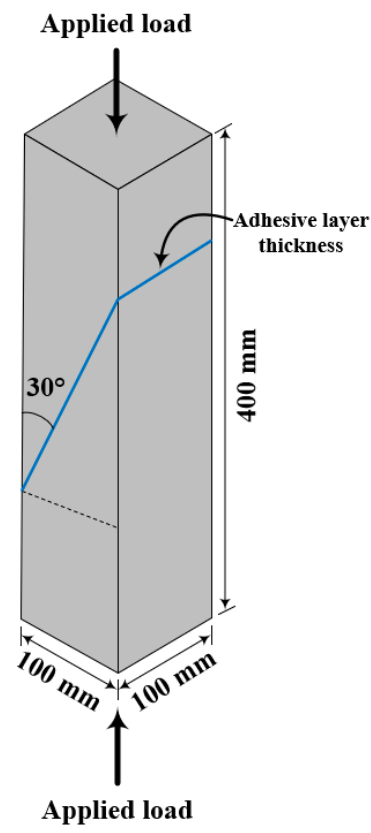

Figure 1. Specifications for the concrete specimen described in BS EN 12615 [20].

\subsection{Epoxy Adhesive}

Epoxy is the most commonly used adhesive in the construction industry. Epoxy adhesive of the bisphenol A type is most often used because of its excellent adhesion and chemical resistance [22]. For this reason, this epoxy adhesive was selected for our experiments. The adhesive strength of the epoxy adhesive is affected by the curing agent used [23]. Three types of hardeners (i.e., modified aliphatic amine, modified cycloaliphatic amine, and modified aromatic amine) were selected for the present work. The first hardener, a modified aliphatic amine, quickly hardens at room temperature and has excellent chemical resistance [24]. Modified cycloaliphatic amine, which is a high-gloss hardener, is chemically resistant and therefore frequently used in tank lining [25]. The final hardener, a modified aromatic amine, is often applied in civil structures due to its substantial strength [26]. The compositions of these three epoxy adhesives are listed below:

- Adhesive 1: Epoxy (Bisphenol A)-Resin (Modified Aliphatic Amine)

- Adhesive 2: Epoxy (Bisphenol A)-Resin (Modified Cycloaliphatic Amine)

- Adhesive 3: Epoxy (Bisphenol A)-Resin (Modified Aromatic Amine)

\subsection{Concrete Specimen Preparation for Slant-Shear Test}

Fresh concrete was poured into the standard specification mold presented in BS EN 12615 to produce the concrete prisms. The specimens were then cut with a sawing machine to create slants in the middle. After cutting the concrete specimens, all foreign matter was removed by the air compressor from the adherend to determine the pure shear strength of the adhesives. To precisely control the adhesive layer thickness, each specimen was then divided into two pieces and put back in the mold. At this point, a waterproof plastic was wrapped around each concrete prism to prevent the liquid adhesive from flowing out before the layer was set. After that, a metal plate of a certain thickness was inserted into the slant to open a gap between each pair of concrete adherends. To completely prevent the adhesive from flowing out, C-clamps were used to tightly hold the mold and waterproof plastic together. After specific gaps were set, the epoxy adhesive prepared for this study was injected into each, forming an adhesive layer with a constant thickness. According to the physical properties of hardeners provided by one manufacturer (Kukdo Chemical, Seoul, Korea), all adhesives begin to cure (i.e., the initial cure) in one hour at $20^{\circ} \mathrm{C}$; the gel time of aliphatic amine is $12 \mathrm{~min}$ [24], cycloaliphatic amine is $50 \mathrm{~min}$ [25], and aromatic amine is $20 \mathrm{~min}$ [26]. However, the specific times the curing of these 
adhesives would be complete (i.e., the final cure) was unclear. Consequently, all adhesives were cured for three days at $20^{\circ} \mathrm{C}$ in order to ensure full curing. As the adhesives were cured, a reference bar was attached perpendicular to each slant; this allowed for measurement of the shear displacement with a linear variable differential transformer (LVDT) when the slant-shear test was executed. This preparation sequence is shown in Figure 2.

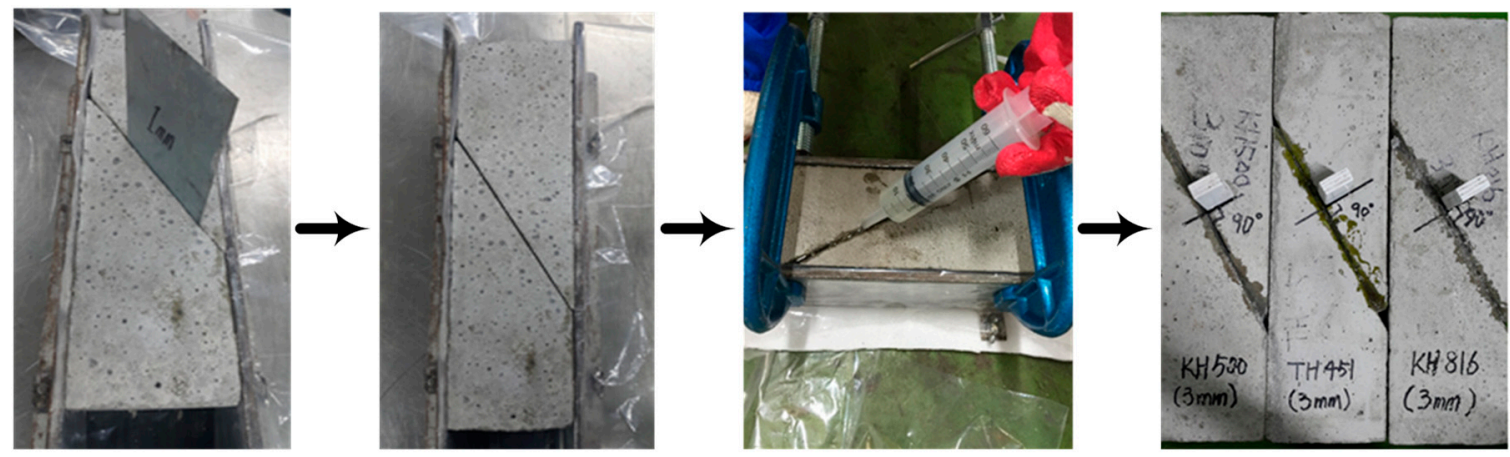

Figure 2. Concrete prism preparation with controlled adhesive layer.

The layer thicknesses of the three types of epoxy adhesive were controlled to be between $1 \mathrm{~mm}$ and $7 \mathrm{~mm}$, as shown in Figure 3. Here, the impact of the curing-induced shrinkage in the epoxy adhesive to the adhesive layer thickness can be neglected because C-clamps were used to tightly hold the concrete specimen. A total of 105 specimens were produced and their shear strengths tested, with 35 concrete prisms assigned to each adhesive. Table 1 shows test variables and number of specimens.
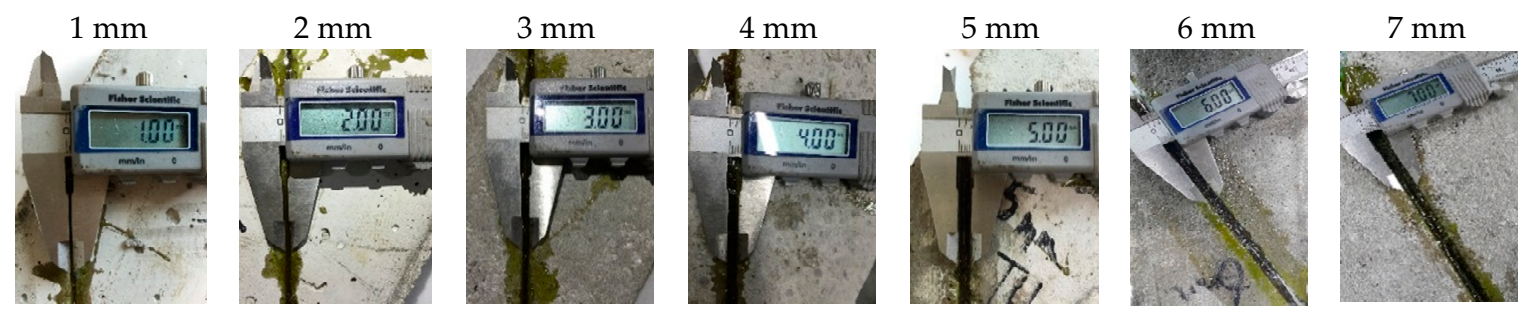

Figure 3. Control of each adhesive layer's thickness.

Table 1. Test variables and number of specimens.

\begin{tabular}{cccc}
\hline Adhesives & $\begin{array}{c}\text { Adhesive Layer } \\
\text { Thickness }\end{array}$ & $\begin{array}{c}\text { Number of Specimens for } \\
\text { Each Layer Thickness }\end{array}$ & $\begin{array}{c}\text { Total Number of } \\
\text { Specimens }\end{array}$ \\
\hline Adhesive 1 & $1-7 \mathrm{~mm}$ & 5 & 35 \\
Adhesive 2 & $1-7 \mathrm{~mm}$ & 5 & 35 \\
Adhesive 3 & $1-7 \mathrm{~mm}$ & 5 & 35 \\
\hline
\end{tabular}

\subsection{Strain Measurements}

Shear strain is defined as the horizontal deformation $(d)$ divided by the vertical distance $(t)$, as shown in Figure 4 [27]. For this study, the horizontal deformation was assumed to be shear displacement, and the vertical distance was presumed to be the adhesive layer's thickness. Thus, the shear strain of the particular epoxy adhesive was defined as the shear displacement divided by the controlled adhesive layer's thickness. The shear displacement was measured with an LVDT when the slant-shear test was executed because the bond layer thickness had already been controlled. 


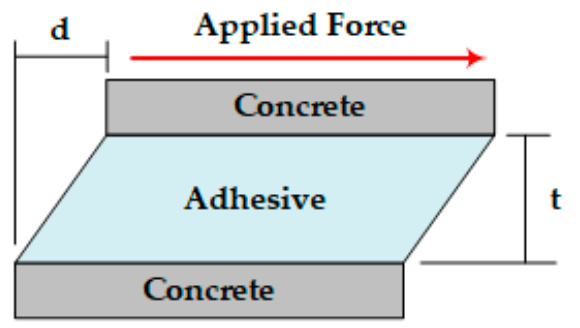

Figure 4. Shear strain mechanism. Where, $d=$ horizontal deformation (shear displacement), $t=$ vertical distance (adhesive layer thickness).

\subsection{Slant-Shear Test}

Each concrete prism was placed in a Universal Testing Machine (Model: HD-201, Gwangju, Gyeonggi, Korea) with an LVDT after the adhesive was completely cured, in order to carry out the slant-shear test (see Figure 5). The load was $2.3 \mathrm{ton} / \mathrm{min}$, controlled to be applied until the moment the adhesive layer began to slide. The Equation (1) [28] was used to convert compressive stress into shear stress.

$$
\tau_{n}=\frac{F}{A} \times \sin (\alpha) \times \cos (\alpha)
$$

where $\tau_{n}$ is the shear stress, $F$ is the magnitude of force, $A$ is the cross-sectional area where force is applied, $\alpha$ is the slant degree from the longitudinal direction of the specimen.

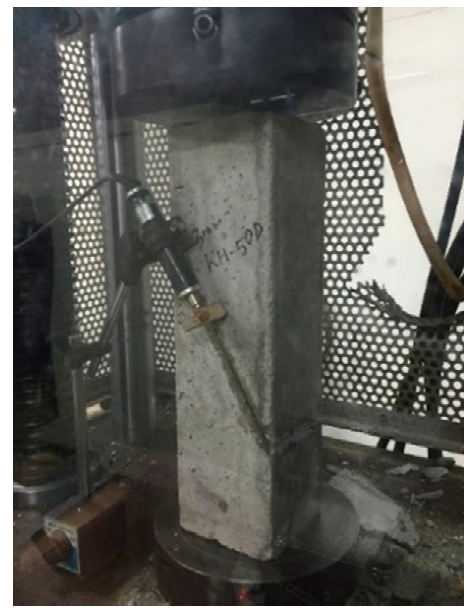

(a)

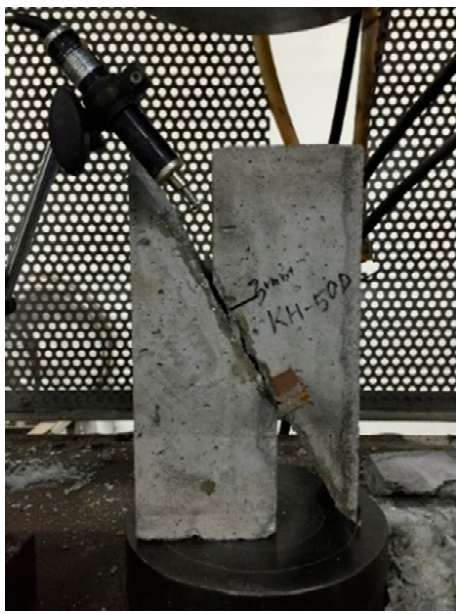

(b)

Figure 5. Slant-shear test with LVDT setup. (a) Before the slant-shear test; (b) After the slant-shear test.

\section{Results and Discussion}

\section{1. (Adhesive 1) Bisphenol A with Modified Aliphatic Amine}

The first epoxy adhesive consisted of bisphenol A and a modified aliphatic amine. The relationship between the shear stress and strain was determined by increasing the adhesive layer's thickness from 1 to $7 \mathrm{~mm}$, as shown in Figure 6. The shear strength developed gradually from 1 to $4 \mathrm{~mm}$. The maximum shear stress developed at $4 \mathrm{~mm}$, but reduced dramatically after the adhesive thickness reached $5 \mathrm{~mm}$. According to the results of the strain measurement, there was no deformation until the moment the bond layer began to slide. After the deformation appeared on the adhesive layer, the shear strength developed only a very little. Through these strain analysis results, it was determined that a brittle fracture appeared without any signs of destruction. 


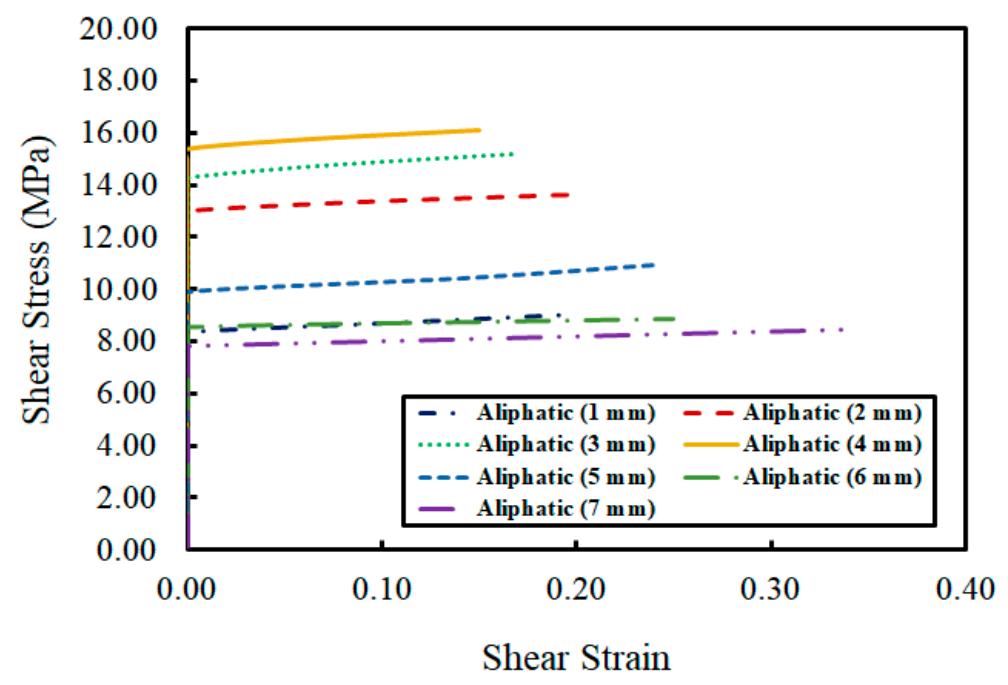

Figure 6. Relationship of shear strain to shear stress in Adhesive 1.

\section{2. (Adhesive 2) Bisphenol A with Modified Cycloaliphatic Amine}

Bisphenol A and a modified cycloaliphatic amine comprised the second epoxy adhesive. The test indicated that the maximum shear stress developed when the thickness of the adhesive layer was $4 \mathrm{~mm}$. The shear stress began to decline when the thickness reached $6 \mathrm{~mm}$, and reached its minimum at $7 \mathrm{~mm}$ (see Figure 7). As with the first adhesive, no shear deformation was found until the moment the adhesive layer broke horizontally. It was also evident that the brittle failure occurred immediately after displacement.

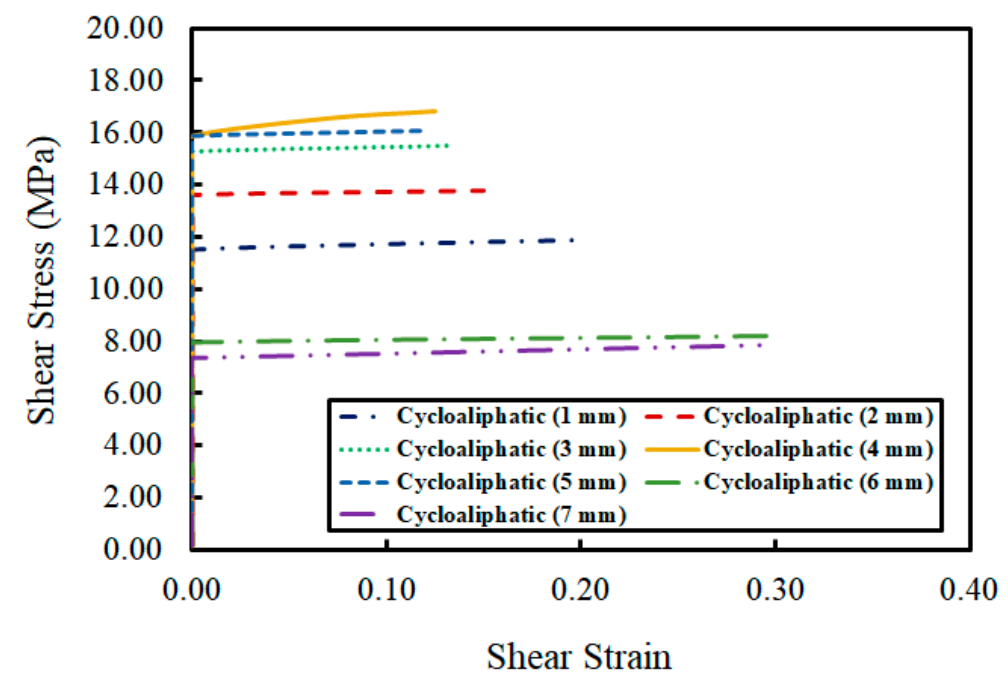

Figure 7. Relationship between shear strain and shear stress for Adhesive 2.

\section{3. (Adhesive 3) Bisphenol A with Modified Aromatic Amine}

The third epoxy adhesive consisted of bisphenol A and a modified aromatic amine. The trend in this experiment was similar to those seen for Adhesives 1 and 2. Its maximum shear stress developed at $4 \mathrm{~mm}$. According to the stress-strain analysis of this adhesive shown in Figure 8, there was no sign of shear deformation until the moment the adhesive began to slide, meaning that the brittle fracture also occurred in the same fashion as the first two epoxy adhesives. 


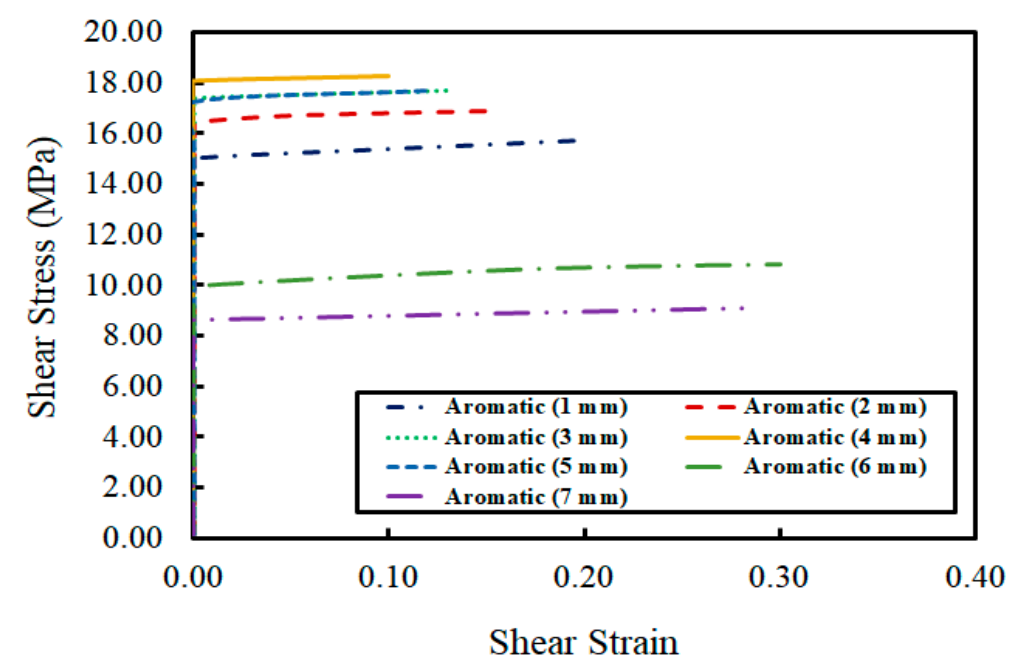

Figure 8. Relationship between shear strain and shear stress for Adhesive 3.

In this study, bisphenol A was mixed with three different types of hardener (i.e., modified aliphatic amine, modified cycloaliphatic amine, and modified aromatic amine) in order to produce three different epoxy adhesives. A total of 105 concrete specimens were employed to determine the shear strengths of the three adhesives. The average maximum shear stress of the first adhesive (bisphenol A and modified aliphatic amine) was $12.02 \mathrm{MPa}$, the second (bisphenol A and modified cycloaliphatic amine) was 13.59 MPa, and the third (bisphenol A and modified aromatic amine) was $15.29 \mathrm{MPa}$. Also, the average yield stresses of the three epoxy adhesives were 10.91, 12.58 and $14.49 \mathrm{MPa}$, respectively. In addition, Table 2 shows the maximum shear stresses measured for the adhesive layers in the concrete specimens, as sorted by adhesive type and thickness. It was determined that the shear resistance tended to increase when the adhesive layer thickness increased from 1 to $4 \mathrm{~mm}$, and decreased when the adhesive layer thickness exceeded $4 \mathrm{~mm}$ shown in Figure 9. This means that the thickness of the adhesive should not exceed $4 \mathrm{~mm}$, regardless of the hardener used. As expected, the maximum shear force that the epoxy layer could withstand varied depending on the type of curing agent used. modified aromatic amine withstood the highest maximum shear force and modified aliphatic amine the lowest.

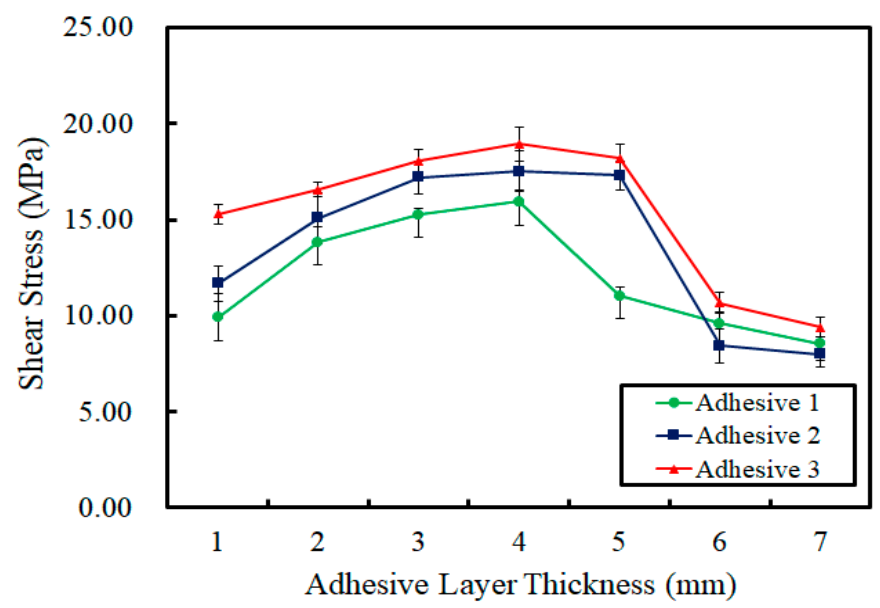

Figure 9. Shear stresses for the adhesive layers between the concrete specimens. 
Table 2. Maximum Shear Stresses (Unit: MPa).

\begin{tabular}{lccccccc}
\hline Thickness & $\mathbf{1} \mathbf{~} \mathbf{m}$ & $\mathbf{2} \mathbf{~} \mathbf{m}$ & $\mathbf{3} \mathbf{~} \mathbf{m}$ & $\mathbf{4} \mathbf{~} \mathbf{m}$ & $\mathbf{5} \mathbf{~} \mathbf{m}$ & $\mathbf{6} \mathbf{~} \mathbf{m}$ & $\mathbf{7} \mathbf{~ m m}$ \\
\hline Adhesive 1 & 9.90 & 13.84 & 15.27 & 15.93 & 11.04 & 9.61 & 8.55 \\
Adhesive 2 & 11.66 & 15.07 & 17.20 & 17.51 & 17.29 & 8.42 & 7.98 \\
Adhesive 3 & 15.30 & 16.55 & 17.96 & 18.94 & 18.20 & 10.67 & 9.39 \\
\hline
\end{tabular}

Brittle fractures were observed in all of the concrete specimens along their respective adhesive layers due to adhesive failure. These brittle fractures were experimentally verified through the relationships between the shear stresses and strains for all three epoxy adhesives; there was no change in shear strain with the increase in shear stress. Also, signs of these brittle fractures were not observed before the adhesive layers began to slide. However, the adhesive layer was destroyed when any shear deformation along an adhesive layer occurred. The presence of these brittle fractures was verified through a strain analysis, meaning that the structural stability was primarily handled by the yield stress of the epoxy adhesive. Any shear strength that developed was very minor compared to the yield strength. Hence, shear strength in the plastic region could be omitted after the slope of the adhesive layer began to slide. Therefore, the yield strength of the shear strength was the major strength handling the applied load. Also, the adhesive's failure state was observed after the slant-shear test, in order to determine whether a shear failure occurred. Figure 10a-c show the states of the adhesive surfaces after the shear failure of all the adhesives employed in this study. Crumpling on the remaining epoxy adhesive was observed due to the shear failure.

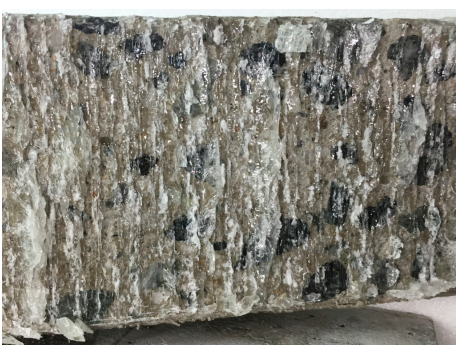

(a)

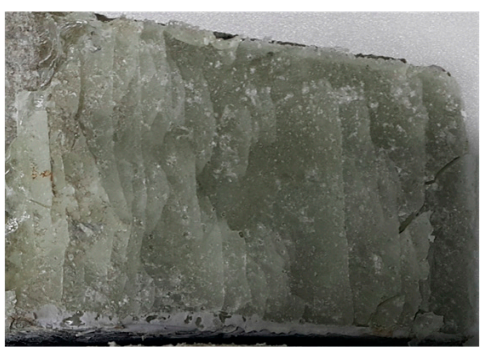

(b)

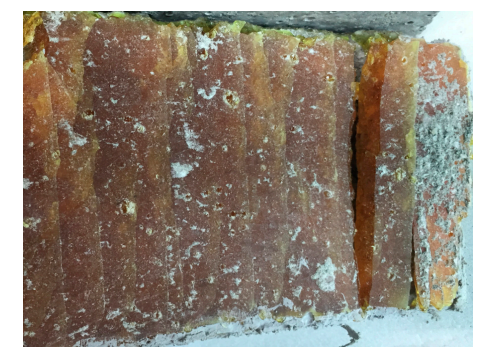

(c)

Figure 10. States on the remaining epoxy adhesive after the shear failure: (a) Adhesive 1; (b) Adhesive 2; (c) Adhesive 3.

\section{Conclusions}

The importance of the amount of adhesive applied to concrete adherends has not been emphasized in the construction industry, even though adhesives are frequently used to repair concrete structures. This topic was experimentally investigated in the present study, which demonstrated that shear strength development was influenced by the thickness of the adhesive layer applied. The main conclusions of the present research are summarized below:

1. The shear strengths of the epoxy adhesives selected for this study increased as the thickness of the adhesive layer applied was increased from 1 to $4 \mathrm{~mm}$. However, the shear strengths decreased once the layer thickness exceeded $4 \mathrm{~mm}$. The maximum strengths of the epoxy adhesives tested in this study developed at a layer thickness of $4 \mathrm{~mm}$ when the adhesives were applied to concrete adherends.

2. A brittle fracture occurred immediately after the shear deformation was measured by LVDT, without any signs of the adhesive layer being destroyed.

3. Overall, the shear strengths developed by Adhesive 3 (bisphenol A with modified aromatic amine) were stronger than those of Adhesive 1 (modified bisphenol A with aliphatic amine) or Adhesive 2 (modified bisphenol A with cycloaliphatic amine). Thus, among the three types of 
adhesive tested in this study, Adhesive 3 (bisphenol A with modified aromatic amine) would be the most appropriate for application to concrete structures in heavy/civil projects.

It is difficult to precisely limit adhesive layer thickness to $4 \mathrm{~mm}$ at construction job sites because epoxies and resins are liquids. However, in order to improve the shear strength of adhesives applied to concrete structures, the amount applied should be sufficient to establish a certain level of thickness between the two concrete adherends. Also, in the present research, brittle fractures were found to occur without any warning signs. Hence, it is important to establish optimal conditions when connecting two concrete adherends, in order to increase the shear strength of the adhesive applied. Therefore, a sufficient amount of adhesive should be applied to achieve the required thickness in the adhesive layer.

Author Contributions: Conceptualization, J.Y. and J.K.; Design of the experiments, J.Y. and J.K.; Performance of the experiments and analysis of the data, J.Y. and K.K.K.; Writing—original draft, J.Y. and Y.S.; Writing-review and editing, Y.S.

Funding: This research received no external funding.

Acknowledgments: Authors sincerely thank the Institute for Advanced Construction Materials of Kangwon National University for materials and technical supports.

Conflicts of Interest: The authors declare no conflicts interest.

\section{References}

1. Smith, T.; Maillard, P.-L. The Sustainable Benefits of Concrete Pavement. In Proceedings of the 42e Congrès annuel de l'AQTR, Montreal, QC, Canada, 2-4 April 2007.

2. Center for Transportation Research. Available online: https://ctr.utexas.edu/wp-content/uploads/pubs/5_ 5110_01_1.pdf (accessed on 28 June 2019).

3. Coppola, L.; Coffetti, D.; Crotti, E.; Pastore, T. Csa-based portland-free binders to manufacture sustainable concretes for jointless slabs on ground. Constr. Build. Mater. 2018, 187, 691-698. [CrossRef]

4. R\&E Gateway. Available online: https:/apps.dtic.mil/dtic/tr/fulltext/u2/a199225.pdf (accessed on 28 June 2019).

5. Davies, P.; Sohier, L.; Cognard, J.-Y.; Bourmaud, A.; Choqueuse, D.; Rinnert, E.; Creachcadec, R. Influence of Adhesive Bond Line Thickness on Joint Strength. Int. J. Adhes. Adhes. 2009, 29, 724-736. [CrossRef]

6. Bryant, R.W.; Dukes, W.A. The Effect of Joint Design and Dimensions on Adhesive Strength. Soc. Aut. Eng. 1967, 670855, 1-9.

7. Chai, H. Deformation and Failure of Adhesive Bonds under Shear Loading. J. Mater. Sci. 1993, 28, $4944-4956$. [CrossRef]

8. R\&E Gateway. Available online: https://apps.dtic.mil/dtic/tr/fulltext/u2/a393056.pdf (accessed on 28 June 2019).

9. Gleich, D. Stress Analysis of Structural Bonded Joints. Master's Thesis, Imperial College, London, England, 2002.

10. Chai, H. Rate and Temperature on the Deformation and Fracture of Structural Adhesives under Shear Loading, The Effects of Bond Thickness. Int. J. Fract. 2004, 130, 497-515. [CrossRef]

11. Jarry, E.; Shenoi, R.A. Performance of butt strap joints for marine applications. Int. J. Adhes. Adhes. 2006, 26, 162-176. [CrossRef]

12. Silva, L.; Carbas, R.; Critchlow, G.W.; Figueiredo, M.; Brown, K. Effect of Material, Geometry, Surface Treatment and Environment on the Shear Strength of Single Lap Joints. Int. J. Adhes. Adhes. 2009, 29, 621-632. [CrossRef]

13. Arenas, J.M.; Narbon, J.J.; Alia, C. Optimum Adhesive Thickness in Structural Adhesives Joints using Statistical Techniques based on Weibull Distribution. Int. J. Adhes. Adhes. 2010, 30, 160-165. [CrossRef]

14. Afendi, J. Study on Effect of Bond Thickness upon Adhesive Strength and Fracture Characteristics of Brittle Epoxy Adhesively Bonded Dissimilar Joint. Ph.D. Thesis, University of Tsukuba, Tsukuba, Japan, 2011.

15. Aydin, S.; Solmaz, M.; Turgut, A. The Effects of Adhesive Thickness, Surface Roughness and Overlap Distance on Joint Strength in Prismatic Plug-In Joints attached with Adhesive. Int. J. Phy. Sci. 2012, 7, 2580-2586.

16. Banea, M.D.; Silva, L.F.; Campilho, R.D. The Effect of Adhesive Thickness on the Mechanical Behavior of a Structural Polyurethane Adhesive. J. Adhes. 2015, 91, 331-346. [CrossRef] 
17. ASTM D1002-10(2019). Standard Test Method for Apparent Shear Strength of Single-Lap-Joint Adhesively Bonded Metal Specimens by Tension Loading (Metal-to-Metal); ASTM International: West Conshohocken, PA, USA, 2019.

18. ASTM D3163-01(2014). Standard Test Method for Determining Strength of Adhesively Bonded Rigid Plastic Lap-Shear Joints in Shear by Tension Loading; ASTM International: West Conshohocken, PA, USA, 2014.

19. Ferdous, W.; Manalo, A.; Aravinthan, T. Bond behavior of composite sandwich panel and epoxy polymer matrix: Taguchi design of experiments and theoretical predictions. Constr. Build. Mater. 2017, 145, 76-87. [CrossRef]

20. BS EN 12615:1999. Products and Systems for the Protection and Repair of Concrete Structures. Test methods. Determination of Slant Shear Strength; London BSI British Standards: London, UK, 1999.

21. ASTM C882/C882M-13a. Standard Test Method for Bond Strength of Epoxy-Resin Systems Used with Concrete by Slant Shear; ASTM International: West Conshohocken, PA, USA, 2013.

22. YD-128. Standard Liquid Epoxy Resin. Available online: http://www.kukdo.com/file/goods/YD-128_TDS_1. pdf (accessed on 28 June 2019).

23. Goodman, S.H. 6-Epoxy Resins. In Handbook of Thermoset Plastics, 2nd ed.; Goodman, S.H., Ed.; William Andrew: Norwich, NY, USA, 1999; Volume 1, pp. 193-268.

24. KH-500. Aliphatic Amine Modified Type. Available online: http://www.kukdo.com/file/goods/KH-500_ TDS_2.pdf, (accessed on 28 June 2019).

25. KH-816. Cycloaliphatic Amine Modified Type. Available online: http://www.kukdo.com/file/goods/KH-816_ TDS_2.pdf (accessed on 28 June 2019).

26. TH-451. Aromatic Amine Modified Type. Available online: http://www.kukdo.com/file/goods/TH-451,452 TDS_2.pdf (accessed on 28 June 2019).

27. Gere, J. Mechanics of Materials, 6th ed.; Thomson Educational Publishing, Inc.: Toronto, ON, Canada, 2004; p. 38.

28. Harris, D.; Carbonell Muñoz, M.; Gheitasi, A.; Ahlborn, T.; Rush, S. The Challenges Related to Interface Bond Characterization of Ultra-High-Performance Concrete with Implications for Bridge Rehabilitation Practices. Adv. Civil Eng. Mater. 2014, 4, 75-101. [CrossRef]

(C) 2019 by the authors. Licensee MDPI, Basel, Switzerland. This article is an open access article distributed under the terms and conditions of the Creative Commons Attribution (CC BY) license (http://creativecommons.org/licenses/by/4.0/). 